\title{
Myopia, Light and Circadian Rhythms
}

\author{
John R. Phillips, Simon Backhouse and Andrew V. Collins \\ Department of Optometry and Vision Science, The University of Auckland \\ New Zealand
}

\section{Introduction}

Myopia has been investigated scientifically for over a century but the search for an effective remedy has been manifestly unsuccessful. The prevalence of myopia in developed societies has now risen to about 30\% in USA (Vitale, Sperduto et al. 2009) and up to $70 \%$ in some Asian centres (Lin, Shih et al. 2004). In addition to the socio-economic burden of providing optical corrections for myopia, common myopia limits career choice and increases the risk of glaucoma and cataract. High myopia also increases the risk of retinal detachment, chorioretinal degeneration and subsequent visual impairment (Saw, Gazzard et al. 2005). Both genetic and environmental factors have been implicated in the aetiology of myopia. Children with myopic parents have a higher than normal risk of developing myopia (Mutti, Mitchell et al. 2002) and twin studies show a higher level of concordance of common myopia in monozygotic compared to dizygotic twins (Dirani, Chamberlain et al. 2006). However, the rapid rise in myopia prevalence over recent decades argues strongly that changing environmental factors also play an important role in the aetiology of myopia.

In the early 1900s Fuchs asserted 'The following means are advised to put a stop to the extension of myopia in schools. First, the excess of work which many scholars have at present to struggle with should be reduced'... 'Instruction ought not to begin too early (if possible not before the completion of the sixth year) and more time should be allotted to bodily exercise, especially in the open air, than has hitherto been the case.' (Duane 1919). Although the long-held view that myopia primarily results from too much near-work is now regarded as an over-simplification, several recent studies support Fuchs's idea that outdoor activity may have an important role in protecting against myopia.

There have been many attempts to inhibit the progression of myopia in children. More recently, these have included treatment with antimuscarinic agents such as atropine eyedrops (Chua, Balakrishnan et al. 2006) and optical devices including multifocal spectacle lenses (Gwiazda, Hyman et al. 2003), dual-focus contact lenses (Anstice and Phillips 2011) and orthokeratology (Kakita, Hiraoka et al. 2011). However, none of these approaches entirely arrests myopia progression in the long term and the vast majority of myopia is managed by optical correction alone. Although conventional optical corrections including refractive surgery restore acuity, they do not prevent the abnormal enlargement of the myopic eye, so children with myopia remain at increased risk of ocular disease later in life.

In this review we examine evidence from human and animal studies that one aspect of outdoor activity, namely exposure to natural light, may reduce the prevalence and 
progression of myopia. We focus on the timing of light exposure in relation to the circadian cycle and on the potential roles of dopamine and melatonin in control of ocular growth and refractive development.

\section{Human myopia and light}

\subsection{Outdoor activity}

Current epidemiological research, as quantified by validated surveys, supports the idea that time spent in outdoor activities has a beneficial effect in reducing myopia prevalence in children and young adults (Jones, Sinnott et al. 2007; Rose, Morgan et al. 2008a; Rose, Morgan et al. 2008b). Whether the effect derives predominantly from increased natural light exposure or increased activity (e.g. sport) or from greater viewing distances outdoors has yet to be ascertained. An association between greater physical activity and reduced myopia progression has been reported in university students (Jacobsen, Jensen et al. 2008) although this association may have been confounded by other factors in the outdoor environment where much of the activity took place. Other studies have found an association between increased outdoor hours and lower myopia even when time spent playing sport outdoors was excluded (Rose, Morgan et al. 2008a). Moreover, indoor sport appears to have no beneficial effect (Rose, Morgan et al. 2008a; Dirani, Tong et al. 2009) suggesting that physical activity alone cannot account for the effect of outdoor activity. Whether the increased viewing distance typically associated with being outdoors has a positive effect in reducing myopia is unknown. The idea that time spent outdoors may act beneficially by substituting for time spent in near and mid-working distance activities seems not to be the case (Rose, Morgan et al. 2008a). In relation to distance viewing outdoors, the accommodative demand for viewing beyond about 6 metres is minimal. Indoor environments, particularly in city apartments, inevitably restrict viewing distance and typically include low dioptric stimuli for accommodation over the peripheral visual field (Charman 2011). However, the most obvious difference between spending time outdoors and time indoors is in light exposure. The spectral composition of light outdoors includes large amounts of ultraviolet (UV) and infrared (IR) in addition to light in the visible spectrum. Indoors, the UV portion of the spectrum is largely absent and if incandescent lighting is used the composition of the light is often biased towards the red end of the spectrum. Light intensity indoors is rarely more than 800 lux, whereas outdoor light intensity is around 50,000 lux on a sunny, blue-sky day and is rarely less than 5,000 lux, even when overcast. The cumulative light exposure for one hour spent outdoors is thus very much greater than for one hour spent indoors (Backhouse, $\mathrm{Ng}$ et al. 2011). This increased light exposure during the day is generally believed to be the most likely basis for the beneficial effect of outdoor activity in reducing myopia prevalence (Rose, Morgan et al. 2008a).

\subsection{Light at night}

Between birth and 2 years of age, the normal eye grows very rapidly, with axial length increasing at a rate of about $2 \mathrm{~mm} /$ year before slowing to about $0.1 \mathrm{~mm} /$ year until the eye reaches adult size (Larsen 1971). It has been suggested that environmental influences acting in this early period of rapid eye growth may potentially affect refractive development later in life. Quinn et al. (Quinn, Shin et al. 1999) investigated the effects of light exposure early in life on refractive status later in childhood. Their study, which was based on a questionnaire 
completed by parents of children aged 2-16 years (median 8 years) on their child's nighttime light-exposure, reported a strong, dose-dependent association between the prevalence of myopia at the time of the study and night-time lighting conditions experienced by the children before the age of 2 years. Remarkably, $55 \%$ of children who slept with the room lights on developed myopia whereas $34 \%$ of children who slept with night-lights, and $10 \%$ of children who slept in darkness, had developed myopia at the time of the study. On the statistical strength of their findings, the authors suggested that the absence of a daily period of darkness could be a precipitating factor in the later development of myopia. A similar study (Czepita, Goslawski et al. 2004) also reported increased prevalence of myopia in children who had experienced ambient light at night before the age of 2 years. However, several studies in different parts of the world, also based on parental questionnaires, have reported no difference in prevalence of myopia in children sleeping in darkness or with ambient light at night before the age of 2 years (USA (Gwiazda, Ong et al. 2000; Zadnik, Jones et al. 2000), Asia (Saw, Zhang et al. 2002), UK (Guggenheim, Hill et al. 2003)). Both studies from the USA found associations between the number of myopic parents in the family and nursery lighting experienced by the child before the age of 2 years, suggesting that the results obtained by Quinn et al. may have been confounded by the uncontrolled effect of parental myopia. However, exposure to light at night may also affect the refractive development of young adults. A study of law students (Loman, Quinn et al. 2002) reported an association between increased myopia progression during law school with less daily exposure to darkness (i.e. more artificial light at night).

\subsection{Season of birth}

Further evidence for the influence of light exposure early in life on later refractive error comes from studies on the effect of season of birth (and by implication perinatal photoperiod) on adult refractive status. In a study population of 276,911 adolescents born in Israel (Mandel, Grotto et al. 2008), moderate and severe myopia prevalence varied by birth month, with the summer months (June/July) being associated with a higher myopia prevalence than the winter months (December/January). Moreover, increasing photoperiod was associated with increasing myopia prevalence in a dose-dependent pattern. Mild myopia was not associated with either season of birth or photoperiod. Birth during the summer was also found to be significantly associated with high myopia in a UK study (McMahon, Zayats et al. 2009) but no association was found between postnatal photoperiod and prevalence of myopia in adulthood. Seasonal variations in photoperiod are particularly extreme above the Arctic Circle. However, in a study of Finnish military conscripts (Vannas, Ying et al. 2003) no associations between myopia prevalence and birth month, global irradiance at birth month or daily hours of darkness during the birth month were found, although there was a trend towards higher prevalence of myopia among conscripts living above the Arctic Circle.

The human data on light exposure and refractive development suggest that increased daytime outdoor light exposure is associated with reduced myopia prevalence whereas increased night-time exposure to artificial light may be associated with increased myopia development - a case of day-light good, night-light bad. The remainder of this review examines the underlying processes which could explain why perturbations in the daily light-dark cycle may affect eye growth and refractive development. 


\section{Light and animal models of myopia}

Animal studies have shown that a diurnal light:dark photoperiod is required for the normal refractive development of the eye in chicks (Li, Troilo et al. 1995; Stone, Lin et al. 1995), tree shrews (Norton, Amedo et al. 2006) and Rhesus monkeys (Smith, Bradley et al. 2001). In normal chick eyes there is a diurnal growth rhythm in which greatest eye elongation occurs during the day with reduced growth rates at night (Weiss and Schaeffel 1993; Nickla, Wildsoet et al. 1998). The choroid also demonstrates a similar diurnal rhythm in which the choroid thins during the day and thickens at night (Papastergiou, Schmid et al. 1998). In eyes deprived of form vision in order to induce myopia, a phase shift occurs in the relationship between the axial length and choroidal rhythms such that peak axial growth occurs earlier than in normal eyes (Nickla, Wildsoet et al. 1998).

\subsection{Effect of constant light}

Rearing chicks under constant light with open eyes produces hyperopia, due to corneal flattening resulting in shallow anterior chambers (Li, Troilo et al. 1995; Stone, Lin et al. 1995). While the anterior chamber becomes shallower, the vitreous chamber lengthens, resulting in no net change in axial length at 2 weeks of age. Continued rearing of chicks in constant light beyond 2 weeks produces macrophthalmos (Oishi, Lauber et al. 1987). The final refractive state may be hyperopic despite the development of significantly deeper vitreous chambers (Li, Troilo et al. 1995). In form-deprived eyes, constant light also produces hyperopia despite overall longer axial lengths and enlarged vitreous chambers in both axial and equatorial directions; (Stone, Lin et al. 1995).

While rearing chicks under continuous light produces hyperopia, the effect is dependent on the level of ambient illumination. Thus, higher light intensities are correlated with higher degrees of hyperopia, lower corneal power and increased vitreous chamber depth. Cohen et al. (Cohen, Belkin et al. 2008) reported that chicks raised under continuous illumination at 10,000 lux for 90 days developed a hyperopic mean refraction of +11.97D, while those raised under 50 lux resulted in an emmetropic mean refraction of $+0.63 \mathrm{D}$. An illumination level of 500 lux also produced a relatively high hyperopic outcome of $+7.90 \mathrm{D}$. While vitreous chamber depth was positively correlated with light intensity, overall axial length did not vary significantly between groups due to the corneal flattening associated with increasing light intensity, resulting in an overall hyperopic refraction at the moderate and high illumination levels (Cohen, Belkin et al. 2008).

Monkeys raised under continuous light conditions (Smith, Bradley et al. 2001) do not exhibit the increase in ocular growth typically found in the chick. Rhesus monkeys raised under continuous light for 6 months developed hyperopic refractions similar in magnitude to animals raised under normal diurnal light cycles. However, the refractions were more variable in outcome, with some animals developing axial anisometropia and low myopia (Smith, Bradley et al. 2001). The authors cautioned that the animals may have been able to re-establish at least a partial diurnal cycle by shielding their eyes during sleep with their arms, although no significant difference in behaviour was observed (Smith, Bradley et al. 2001).

\subsection{Effect of constant darkness}

Rearing chicks in complete darkness also produces hyperopia irrespective of whether a diffusing goggle is worn (Gottlieb, Fugate-Wentzek et al. 1987). The degree of hyperopia 
produced is approximately double that of normal chicks by 42 days. In contrast, tree shrews placed in continuous darkness eventually exhibit a myopic shift in refraction (Norton, Amedo et al. 2006). Although the animals initially stabilise at a low degree of hyperopia following 16 days of normal visual experience after eye opening, a subsequent period of 10 days of continuous darkness results in vitreous elongation and a myopic refraction (Norton, Amedo et al. 2006). While both chicks and tree shrews exhibit ocular growth under constant darkness, the significant corneal flattening which produces hyperopia in chicks does not occur in the tree shrew. Conversely, raising rhesus monkeys in continuous darkness appears to interfere with the emmetropisation process such that they retain their relatively high hyperopic neonatal refractions (Guyton, Greene et al. 1989).

Gottlieb et al. (Gottlieb, Fugate-Wentzek et al. 1987) proposed that two mechanisms may combine under dark-rearing in chicks to produce the hyperopic outcome: a visual deprivation mechanism which triggers enlargement of the eye, as occurs in formdeprivation myopia, and a second photoperiod-related mechanism which results in corneal flattening.

A phase advance in the cycle of eye growth is found in chicks raised under constant darkness which is associated with an overall increase in axial growth and choroidal thinning (Nickla, Wildsoet et al. 2001). As the rhythms in choroidal thinning and axial growth persist under constant darkness, they must be circadian in origin, rather than simply diurnal in response to external light-dark cycles (Nickla, Wildsoet et al. 2001). Nickla (Nickla 2006) provides further evidence for the role of a phase shift in the temporal relationship between axial length and choroidal thickness cycles in the control of ocular growth in a study comparing recovery from form-deprivation, myopic defocus and hyperopic defocus in chicks. It appears that where the treatment requires a decrease in ocular growth (such as recovery from form-deprivation) the axial length and choroidal rhythms shift into phase. The mechanism by which such a phase shift might influence ocular growth is not certain, although it has been proposed that the variation in thickness of the choroid may regulate diffusion of a signal molecule from the retina to the sclera, or may act as a mechanical scaffolding against the influence of diurnal intra-ocular pressure changes on the sclera (Nickla 2006).

\subsection{Diurnal modulation of illumination}

In order to determine the minimum period of darkness within the diurnal light:dark cycle that is required for normal eye growth, $\mathrm{Li}$ et al. (Li, Howland et al. 2000) investigated the effect of various periods of darkness from zero (constant light) to a standard 12:12 $\mathrm{h}$ light:dark cycle in chicks. They found that at least 4 hours darkness per diurnal cycle produced a normal emmetropisation response in the chick (Li, Howland et al. 2000). Further investigations demonstrated that the 4 hours of darkness was most effective in blocking the effects of excess light exposure when presented in a single period at the same time of day, rather than at random times or as multiple periods totalling 4 hours (Li, Howland et al. 2000). Li et al. (Li, Howland et al. 2000) concluded that this period of darkness may be sufficient to entrain the intrinsic circadian clock of the avian retina (Morgan and Boelen 1996). The requirement for periods of darkness during a diurnal cycle in order to produce normal eye growth in chicks has a potential corollary in humans. As noted earlier, the use of night lights in children's bedrooms under the age of 2 years has been associated with the development of myopia in later life (Quinn, Shin et al. 1999). 
Diurnal modulation of ambient illumination rather than the need for periods of total darkness may be the significant requirement for normal emmetropisation in chicks. Liu et al. (Liu, Pendrak et al. 2004) reared chicks under light:dark, light:dim and constant light cycles with the aim of investigating the effect of ambient lighting at night on emmetropisation. The irradiance of the light phase was $1500 \mu \mathrm{W} / \mathrm{cm}^{2}$, while the dim phase varied between 0.01 and $500 \mu \mathrm{W} / \mathrm{cm}^{2}$. The eyes of chicks raised under light:dark and light:dim cycles had comparable ocular refractions and dimensions. Conversely, rearing under constant light levels from $1 \mu \mathrm{W} / \mathrm{cm}^{2}$ ( 0.3 lux) to $1500 \mu \mathrm{W} / \mathrm{cm}^{2}$ ( $\sim 500$ lux) produced the typical shallow anterior chamber and hyperopic shift in refraction as found previously in chicks. These results imply that the modulation of light levels during a diurnal cycle may be of more importance in the maintenance of the normal emmetropisation response than the absolute light (or dark) levels. Consequently, the use of light:dim diurnal cycles may be a more pertinent paradigm for study as it more closely approximates the typical urban environment with artificial lighting at night (Liu, Pendrak et al. 2004).

\subsection{Amplitude modulation of illumination}

Recent animal investigations support the fundamental hypothesis that light exposure is the mediator of the antimyopiagenic effect of outdoor activity (Rose, Morgan et al. 2008a). Experiments in chicks have shown that exposure to high ambient light levels, either artificial or natural, modifies the development of experimental myopia due to either visual form deprivation using translucent occluders, or induced defocus using spectacle lenses (Ashby, Ohlendorf et al. 2009; Ashby and Schaeffel 2010). While exposure to high illumination levels of 15,000 lux for 5 hours per day significantly reduced form-deprivation myopia by around $60 \%$, in lens-induced myopia the rate of compensation for the induced defocus was modified, but not the final degree of refractive error produced (Ashby and Schaeffel 2010). The normal emmetropisation process in chicks can also be directly influenced by ambient light levels: raising animals under low light levels (50 lux) produced myopic refractive outcomes on average, while high light levels (10,000 lux) produced hyperopic refractive outcomes (Cohen, Belkin et al. 2011).

In form-deprivation experiments in chicks, exposure to high artificial light (15,000 lux) indoors or natural light (30,000 lux) outdoors for 15 minutes per day with occluders removed was sufficient to produce a statistically significant decrease in axial myopia beyond that produced by the removal of the occluders under normal laboratory light levels (500 lux) (Ashby, Ohlendorf et al. 2009). The antimyopiagenic effect of high illumination levels was also demonstrated under constant occluder wear conditions where a significant decrease in axial myopia development was also demonstrated in chicks raised under 15,000 lux for 6 hours per day when compared to animals raised under 50 or 500 lux (Ashby, Ohlendorf et al. 2009). As the antimyopiagenic effect occurred during continuous occluder wear the authors conclude that the effect cannot be due to a reduction in image blur resulting from pupil constriction as these animals did not receive clear form vision at any time in the occluded eye. It has been suggested that high ambient illumination levels may affect the diurnal variation in retinal dopamine, which is disrupted in form-deprivation in chicks (Weiss and Schaeffel 1993), with the proposal that the chick retina has a graded release of dopamine under high illumination levels which results in a retardation of myopia development (Ashby, Ohlendorf et al. 2009). The intra-vitreal administration of a dopamine antagonist (spiperone) blocked the protective effect of high illumination levels against form- 
deprivation myopia in chicks (Ashby and Schaeffel 2010) further supporting the hypothesis that this neurotransmitter is intrinsically involved in the control of the emmetropisation mechanism (Ashby and Schaeffel 2010; Mao, Liu et al. 2010; Nickla, Totonelly et al. 2010).

\subsection{Chromaticity and refractive development}

The contribution of the chromatic component of light to refractive development has been investigated in a number of animal models including chicks (Rucker and Wallman 2009), fish (Kroger and Wagner 1996) and guinea pigs (Long, Chen et al. 2009). Guinea pigs raised under long-wavelength light (peak at $760 \mathrm{~nm}$ ) reportedly develop a significant degree of myopia, associated with a significant increase in vitreous chamber depth, over a period of 4 weeks when compared to animals raised under mixed-wavelength light (unfiltered halogen lamps) (Long, Chen et al. 2009). The myopiagenic effect of long-wavelength light was reversed by allowing the animals to recover under mixed-wavelength light conditions for two weeks, after which there was no significant difference in refraction (Long, Chen et al. 2009).

One possible explanation for the effect of wavelength on refractive outcome is based on the intrinsic chromatic aberration of the vertebrate eye (Mandelman and Sivak 1983) which could provide a sign-of-defocus signal for emmetropisation (Flitcroft 1990) as the long and short wavelength components would produce relative hyperopic and myopic defocus of the retinal image respectively. For example, in a comparison of the effects of raising guinea pigs under equiluminant short wavelength light $(430 \mathrm{~nm})$ or middle wavelength light $(530 \mathrm{~nm})$, Liu et al. (Liu, Qian et al. 2011) demonstrated that after 12 weeks the $530 \mathrm{~nm}$ group was less hyperopic due to faster vitreous elongation, while the $430 \mathrm{~nm}$ group was more hyperopic following slower vitreous elongation. The difference in refraction between the groups $(4.50$

D) exceeded the longitudinal chromatic aberration of the guinea pig eye (approximately 1.5

D) at the selected wavelengths, which was possibly due to additional accommodative effects produced by the monochromatic illumination (Seidemann and Schaeffel 2002), or by wavelength-dependent alteration of retinal or retinal pigment epithelium growth signals (Liu, Qian et al. 2011).

\section{Light and circadian rhythms}

The role of illumination level and the requirement for periodic light:dark cycles during normal refractive development points to a role for the intrinsic circadian clock and the associated dopamine-melatonin cycle in the control of eye growth (Cahill and Besharse 1995; Witkovsky 2004; Iuvone, Tosini et al. 2005). The presumed role of circadian rhythms, which persist in constant darkness independent of the diurnal light:dark cycle, is to regulate the timing of biological events so as to optimise the metabolic function and energy use of the organism (Roenneberg and Foster 1997; Levi and Schibler 2007).

\subsection{The circadian pacemaker}

Although the control of the circadian rhythm is a complex, multivariate process, it has been known for some time that light plays a pivotal role (Iuvone, Tosini et al. 2005). The underlying circadian rhythm is controlled by a circadian clock, through the expression of "clock genes" and their products, and entrainment cues known as zeitgebers ("time givers") 
which influence the timing of these rhythms (Roenneberg and Foster 1997; Iuvone, Tosini et al. 2005). The primary, central time keeping clock in the body is the suprachiasmatic nucleus (SCN) of the hypothalamus (Roenneberg and Foster 1997). The primary input to the $\mathrm{SCN}$ is from the retina via the retinohypothalamic tract (RHT) (Simonneaux and Ribelayga 2003), which makes light the primary zeitgeber for entrainment of the circadian rhythm (Roenneberg and Foster 1997). While input via the RHT is not necessary for the generation of a circadian rhythm (evidenced by the free running nature of the SCN rhythm), it is necessary for the entrainment of the circadian rhythm to the normal light:dark cycle (Inouye and Kawamura 1979).

\subsection{The light entrainment pathway}

The traditional view of the photosensitive retinal organisation is of a dual photoreceptor system comprising both rods and cones. However, circadian entrainment has been found to originate from a small subset of retinal ganglion cells, the intrinsically photosensitive retinal ganglion cells (ipRGCs) (Berson, Dunn et al. 2002; Hattar, Liao et al. 2002). The photopigment melanopsin, first described in melanophores on frog skin and subsequently found in the inner retina of a number of mammals including humans, provides the ipRGCs with this photosensitivity (Provencio, Rodriguez et al. 2000; Hattar, Liao et al. 2002). Melanopsin has an action spectrum that peaks around $480 \mathrm{~nm}$ (Berson, Dunn et al. 2002). However, studies in melanopsin-knockout mice showed that melanopsin is not essential for light entrainment of the circadian pacemaker, but improves the magnitude of the response (Ruby, Brennan et al. 2002). It transpires that the melanopsin-containing ipRGCs also receive input from the traditional rod and cone photoreceptors (Perez-Leon, Warren et al. 2006). There is a loss of photo-entrainment, but a persistence of pattern vision, in animals without functional ipRGCs providing definitive support for the role of the ipRGCs in the entrainment of the circadian system by light (Guler, Ecker et al. 2008). The entrainment of the circadian system in mammals is thus mediated by the ipRGCs as a balance between intrinsic photoreception enabled by melanopsin and input from the traditional retinal photoreceptors. In chicks melanopsin is found in both the retina and the pineal gland, indicating light can entrain the circadian pacemaker through both retinal (via ipRGCs) and direct pineal routes (Torii, Kojima et al. 2007; Neumann, Ziegler et al. 2008).

The SCN, working as a central master clock, controls the circadian timing of the organism through a multisynaptic pathway. The SCN projects to neurones in the paraventricular hypothalamic nucleus, which synapse preganglionic sympathetic neurons in the intermediolateral cell column, stimulating postganglionic sympathetic neurons in the superior cervical ganglion, before finally providing sympathetic input to the pineal gland (Larsen, Enquist et al. 1998). The main circadian mediator from the pineal gland is melatonin, a hormone first isolated from bovine pineal glands and named for its ability to lighten the melanocytes in frog skin (Lerner, Case et al. 1958). Melatonin acts through melatonin receptors in a diverse range of tissues, performing a variety of roles in circadian entrainment, endocrine functions, cardiovascular responses, the immune system, and ocular physiology (Alarma-Estrany and Pintor 2007).

\subsection{Melatonin precursors}

Melatonin (N-acetyl-5-methoxytryptamine) is a circadian hormone produced through a pathway involving four precursor intermediaries (Fig. 1.). All of the components necessary 
for the production of melatonin are active within the pineal gland, which is the main site of production (Axelrod 1974; Zawilska, Skene et al. 2009). The first step is the conversion of the dietary amino acid tryptophan to 5-hydroxytryptophan by the enzyme tryptophan hydroxylase (TPH); the second step involves the conversion of 5-hydroxytryptophan to serotonin via the enzyme aromatic L-amino acid decarboxylase (AADC); serotonin is converted in the third step to $\mathrm{N}$-acetylserotonin by the enzyme arylalkylamine- $\mathrm{N}$ acetyltransferase (AANAT); the final step is the O-methylation of $\mathrm{N}$-acetylserotonin to melatonin by the enzyme hydroxyindole-O-methyltransferase (HIOMT). The rate limiting enzyme in the production of melatonin is widely thought to be AANAT, although recent work suggests that HIOMT may be the crucial limiting factor (Liu and Borjigin 2005). The precursor components of melatonin synthesis also show inherent circadian rhythms of production (Axelrod 1974). The retina is another significant producer of melatonin in some animals, providing the basis for a peripheral clock in addition to the central clock of the pineal gland (Iuvone, Tosini et al. 2005)

Tryptophan

$$
\downarrow \text { Tryptophan hydroxylase (TPH) }
$$

5-hydroxytryptophan

$$
\downarrow \text { Aromatic }_{\mathrm{L}} \text {-amino acid decarboxylase (AADC) }
$$

Serotonin

(5-hydroxytryptamine)

Arylalkylamine-N-acetyltransferase (AANAT)

$\mathrm{N}$-acetylserotonin

Hydroxyindole-O-methyltransferase (HIOMT)

Melatonin

(N-acetyl-5-methoxytryptamine)

Fig. 1. Melatonin production pathway showing the precursor compounds and the enzymes involved.

\subsection{Circadian melatonin rhythms}

In the majority of species studied to date, whether they are diurnally or nocturnally active, there is a circadian secretion pattern of melatonin with high levels present at night and low levels during the day (Zawilska, Skene et al. 2009). The onset of darkness following a period 
of light leads to an increase in pineal AANAT and melatonin levels in phase with each other (Wilkinson, Arendt et al. 1977). However, there appears to be a refractory period for darkinduced melatonin rises such that darkness during periods when the organism is expecting it to be light does not induce the rise (Binkley, Macbride et al. 1975). Three distinct patterns of nocturnal melatonin production have been described in mammals: Type A is uncommon and represents a peak in melatonin late in the dark phase (e.g. Syrian hamster and house mouse); Type B is most common and shows peak melatonin expression occurring around midnight (e.g. rat, guinea pig, and human); and Type $C$ which is also common and shows elevated melatonin levels for most of the dark phase (e.g. sheep and cat) (Zawilska, Skene et al. 2009). The human melatonin cycle, like that of animals (Tast, Love et al. 2001), can be entrained to variations in the light:dark cycle. When the light:dark cycle is phase-shifted by 12 hours, the human rhythm in melatonin secretion re-entrains to the new dark phase over a period of 5 to 7 days (Lynch, Jimerson et al. 1978).

\subsection{Light and melatonin suppression}

Darkness is required for the rise in melatonin, as animals kept in constant light show a reduction or complete loss of melatonin synthesis (Perlow, Reppert et al. 1980). However, the factor mediating the entrainment of the melatonin rhythm appears to be light exposure. Presentation of light during the dark phase, when melatonin levels are elevated, results in a rapid suppression of production and a reduction in serum melatonin concentration (e.g. (Illnerova, Backstrom et al. 1978; Rollag, O'Callaghan et al. 1978)). Human melatonin suppression by light is intensity dependant, with brighter light leading to greater levels of melatonin suppression (McIntyre, Norman et al. 1989; Zeitzer, Dijk et al. 2000). Suppression to near daytime levels (67\% suppression) is achieved with 1000 lux (McIntyre, Norman et al. 1989), while a half maximal suppression response can be seen between approximately 50 and 130 lux (Zeitzer, Dijk et al. 2000). This light induced suppression also shows an inverse correlation with duration, such that longer durations of light require lower intensities of light to induce suppression (Aoki, Yamada et al. 1998). However, independent of light level there appears to be an asymptote for melatonin suppression after around 60 minutes of light exposure (Figueiro, Rea et al. 2006). Interestingly the melatonin suppression by light appears to be sensitised/desensitised by the amount of light received during the day prior, such that less light exposure (as experienced during winter months) results in much greater melatonin suppression for a given amount of light at night (Smith, Schoen et al. 2004; Higuchi, Motohashi et al. 2007).

The action spectrum for melatonin suppression shows peak effect between 446 and $477 \mathrm{~nm}$ (Brainard, Hanifin et al. 2001; Thapan, Arendt et al. 2001). The light response of the melanopsin containing ipRGCs mirrors that of the melatonin suppression action spectrum, indicating that these cells are the likely mediators of the response (Berson, Dunn et al. 2002). Circadian photo-entrainment also appears to be mediated by a peak action spectrum response from the same blue wavelength portion of the spectrum (Hattar, Lucas et al. 2003). These responses are also seen in humans, although a greater response is seen when polychromatic light is used instead of monochromatic light at peak melanopsin sensitivity, suggesting melanopsin may not be solely responsible and that rod and cone input also play a role (Revell and Skene 2007). Despite uncertainty as to the exact cellular input driving the circadian entrainment, it is clear that the blue end of the spectrum is important. Interestingly, exposure to the blue part of the spectrum also appears to suppress myopia development in guinea pigs (e.g. (Liu, Qian et al. 2011; Wang, Zhou et al. 2011)). 
Wang et al. (Wang, Zhou et al. 2011) raised guinea pigs under blue light (480 nm), green light $(530 \mathrm{~nm})$ and broadband white light. After 10 days the levels of melatonin in the pineal glands were significantly lower in both the blue light and white light groups when compared to the green light group. This difference existed in both daytime $(10 \mathrm{am})$ and night-time $(10 \mathrm{pm})$ samples. The green-light group were also about $2 \mathrm{D}$ more myopic, had greater axial lengths and greater vitreous depths than the other groups. Furthermore the green-light group exhibited reduced expression of retinal melanopsin mRNA and reduced levels of melanopsin protein. MT1 receptor mRNA expression was higher in both the retina and sclera of the green-light group. Overall this study demonstrated a clear link between wavelength of illumination, refractive error development and modulation of the melatonin pathway in guinea pigs.

\subsection{Light as a zeitgeber}

Light is the primary zeitgeber for the entrainment of the circadian system (Roenneberg and Foster 1997). Phase response curves have shown that the timing of light exposure is critical to circadian responses to light (Daan and Pittendrigh 1976). When light is presented at the beginning of the subjective night there is a phase delay of the subsequent activity-rest cycle, while light presented at the end of the subjective night leads to a phase advance. Presentation of light during the subjective day has little effect on the phase response curve, suggesting the twilight zones of dusk and dawn are the key times for entrainment (Roenneberg and Foster 1997). The phase shifting effect of light also affects the timing of the dim light melatonin onset (the increase in melatonin levels at night) (Lewy, Sack et al. 1985). Bright light in the evening delays dim light melatonin onset while bright light in the morning advances it. Bright light presented both in the morning and evening gives an intermediate response between delay and advance (Lewy, Sack et al. 1987). Exposure to bright light results in immediate melatonin suppression, but longer exposure of greater intensity is required to entrain the pacemaker (Hashimoto, Nakamura et al. 1996). However, dim light exposure at the appropriate time and for a long enough period has also been shown to entrain the circadian system (Zeitzer, Dijk et al. 2000). The importance of the timing of the signal for entrainment has a parallel in form-deprivation myopia wherein removal of the occluder for 40 minutes in the evening is more effective at reducing the induced myopia than if the occluder is removed in the morning (Ohngemach, Feldkaemper et al. 2001).

\subsection{Photoperiodism and photoperiodic history}

Photoperiodism, the adaptation of an organism's physiological functions to changes in season, is thought to be determined by both the absolute photoperiod length and by changes (either increasing or decreasing) in photoperiod length (Goldman 2001). Three main hypotheses to explain the influence of melatonin on this phenomenon exist: the duration, coincidence, and amplitude hypotheses.

The duration hypothesis proposes that the duration of night-time melatonin release is used as a signal encoding day length, with a shorter duration melatonin signal indicating long day/short night periods and vice versa (Simonneaux and Ribelayga 2003). In pinealectomised animals, short duration infusion of melatonin replicates a long day reproductive response while long duration infusion replicates a short day response (e.g. 
(Bittman and Karsch 1984; Maywood, Buttery et al. 1990)). The coincidence hypothesis proposes that there is a coincidence between a sensitive period for signal detection and the presence of the melatonin signal. Infusion of melatonin at specific circadian time points in pinealectomised individuals suggests a critical period of sensitivity either at the onset of the dark phase (Gunduz and Stetson 2001), or at a specific time after the initial melatonin rise (Pitrosky, Kirsch et al. 1995). More recent work suggests that the coincidence timing effect of melatonin acts through clock gene expression oscillations (for review see (Hazlerigg and Wagner 2006)). While the amplitude hypothesis, which proposes that the peak amplitude of melatonin secretion is the signal for seasonal timing, is often discussed (e.g. (Simonneaux and Ribelayga 2003)), very little experimental data exists to back it up. Thus duration and timing of circadian signals may be more important than signal amplitude for circadian entrainment.

During periods of intermediate day-length between the winter and summer solstices a single day-length signal is insufficient to determine whether the days are becoming longer or shorter, so photoperiodic history, based upon the length of the preceding days, is used. The photoperiodic history appears to rely on the summation of recent photoperiod information over a number of days (Prendergast, Gorman et al. 2000), and the prenatal photoperiod actually appears to modify the postnatal day-length threshold which controls the maximal rate of development (Shaw and Goldman 1995). The ability of the perinatal photoperiodic history to influence future development rates may explain the observed season of birth effect in human refractive development (see Section 2.3).

\section{Peripheral clocks}

In addition to the master central circadian clock, peripheral systems and indeed individual cells also possess clocks (reviewed by (Balsalobre 2002)). Of these the retina, which also provides the main entrainment cue for the central clock, constitutes the most relevant peripheral clock for refractive development. The retina is a highly circadian tissue, showing rhythms in a variety of functions including visual sensitivity, the electroretinogram response, rod outer segment disc shedding, melanopsin mRNA expression, melatonin synthesis, and dopamine synthesis (for excellent reviews see (Iuvone, Tosini et al. 2005; Tosini, Pozdeyev et al. 2008)).

\subsection{Retinal melatonin}

Melatonin is synthesised in the retina in a circadian manner, independent of the SCN, in both non-mammalian (Cahill and Besharse 1992; Thomas, Tigges et al. 1993) and mammalian (Tosini and Menaker 1996) vertebrates. The retinal photoreceptors appear to be the source of this retinal melatonin production, with AANAT and HIOMT activity having been localised mainly to these cells, and only minimal activity in the inner nuclear layer and ganglion cells (Guerlotte, Greve et al. 1996; Coon, Del Olmo et al. 2002). Moreover, melatonin continues to be produced despite partial or complete destruction of the inner retina (Cahill and Besharse 1992; Thomas, Tigges et al. 1993). Human and primate retinas appear to be missing activity of the HIOMT enzyme, with expression of HIOMT mRNA in such small quantities that it contributes little to the production of melatonin (Bernard, Donohue et al. 1995; Coon, Del Olmo et al. 2002). However, labelling and activity of HIOMT in human photoreceptors has been demonstrated (Wiechmann and 
Hollyfield 1987), although this has not been repeated by other groups. It has been postulated that $\mathrm{N}$-acetylserotonin might take the place of a local melatonin signal in the retina of humans and primates (Iuvone, Tosini et al. 2005), or that the signal is provided by circulating melatonin levels (Osol and Schwartz 1984). Interestingly, human RPE and ciliary body also synthesise melatonin (Martin, Malina et al. 1992; Zmijewski, Sweatman et al. 2009).

\subsection{Central and retinal dopamine rhythms}

Dopamine is a neurotransmitter that has a multitude of roles, such as in learning and movement (Witkovsky 2004). Plasma dopamine levels in humans show a circadian rhythm in concentration that is phase-shifted relative to melatonin by approximately 180 degrees, peaking in the light phase and reaching lowest levels during the dark phase (Sowers and Vlachakis 1984). Primates (Perlow, Gordon et al. 1977), rats (Schade, Vick et al. 1995), and birds (Kang, Thayananuphat et al. 2007) also show these circadian rhythms in dopamine production; high in light, low in dark, and out of phase with melatonin. In pinealectomised rats the administration of melatonin suppresses dopamine expression in a dose-dependent manner (Khaldy, Leon et al. 2002).

Dopamine also has many roles in the retina, for example in light adaptation and cell death, as well as a potential role in ocular growth (Witkovsky 2004). As in the brain, retinal dopamine shows a diurnal rhythm with peak levels during the day and low levels during the night in non-human vertebrates (Nowak, Zurawska et al. 1989; Megaw, Boelen et al. 2006), and in human retinas (Di Paolo, Harnois et al. 1987). The diurnal variation in dopamine levels persists in constant darkness in mice, indicating that it has a circadian rhythm of release (Doyle, Grace et al. 2002), although others have found no circadian rhythm but a light activated fluctuation in retinal dopamine (Melamed, Frucht et al. 1984).

\subsection{Light and dopamine}

Dopamine is released from the perfused retina on exposing it to light (Kramer 1971), and light also stimulates retinal dopamine synthesis and turnover (Iuvone, Galli et al. 1978; Cohen, Hadjiconstantinou et al. 1983). Moreover, the light-activated rise in dopamine levels in the retina is much greater than the rise seen with the underlying circadian rhythm in constant darkness (Megaw, Boelen et al. 2006), and the metabolism of dopamine in the light is much greater than in the dark (Parkinson and Rando 1983; Megaw, Boelen et al. 2006). Furthermore, the intensity of light appears to be important for dopamine release and synthesis in the retina, with maximal stimulation and saturation of the response occurring between 32 to 80 lux in rats (Proll, Kamp et al. 1982; Brainard and Morgan 1987).

It transpires that change in light, in the form of flicker, is a more potent stimulus to dopamine release than constant light levels. This effect has been shown in several species, with increasing release rates seen with increasing stimulus presentation rates, and an increase in dopamine release above that seen with constant light alone (Kramer 1971; Weiler, Baldridge et al. 1997). Flickering light appears to increase dopamine release two to three times that of basal release levels. High frequency flicker at $6 \mathrm{~Hz}$ has also been shown to inhibit both form-deprivation myopia and lens-induced myopia in the chick (Schwahn and Schaeffel 1997). The degree of suppression is correlated with the length of the dark 
phase of the flicker duty cycle (Schwahn and Schaeffel 1997). This may be due to increased retinal dopamine levels as 2 hours of exposure to flickering light at $10 \mathrm{~Hz}$ was shown to restore the rate of dopamine synthesis under form-deprivation conditions in chicks, possibly due to increased transcription of the tyrosine hydroxylase gene in dopaminergic amacrine cells (Luft, Iuvone et al. 2004).

\subsection{Dopamine and melatonin}

When light is presented during the dark phase there is a rapid suppression of melatonin and an increase in dopamine to normal daytime levels (Adachi, Nogi et al. 1998). Interestingly, in knockout mice that do not produce melatonin there is a loss of the circadian dopamine rhythm when the animals are maintained in constant darkness, but the rhythm is restored on administering exogenous melatonin (Doyle, Grace et al. 2002). These results are intriguing as they show that in the absence of melatonin a normal dopamine rhythm can be maintained by light exposure in a rhythmic light:dark cycle, but that melatonin can, in the absence of a light driven zeitgeber, also influence dopamine rhythms. Indeed there is a complex interaction between melatonin and dopamine in the retina with mutual inhibitory effects between the two compounds. Intra-vitreal injection of dopamine into the eye at night suppresses melatonin while the injection of melatonin during the day suppresses dopamine (Adachi, Nogi et al. 1998). Melatonin leads to an increase in AANAT activity in the retina and a decrease in dopamine levels (Nowak, Zurawska et al. 1989; Nowak, Kazula et al. 1992), while dopamine inhibits retinal AANAT activity and melatonin release (Iuvone and Besharse 1986; Tosini and Dirden 2000).

As melatonin production has not been demonstrated in the human retina, endogenous melatonin released from the pineal gland potentially acts in the retina. Indeed high levels of melatonin are found in human retinas, and intraperitoneal injection of melatonin in mice leads to an increase in retinal melatonin levels (Osol and Schwartz 1984; Doyle, Grace et al. 2002). In chicks the pineal gland has been shown to have a significant influence over both expression of the dopamine $\mathrm{D}_{2}$-receptor mRNA and dopamine release in the retina (Ohngemach, Feldkaemper et al. 2001). Dopamine has also been shown to increase the expression of melanopsin mRNA via a $\mathrm{D}_{2}$-receptor pathway in ipRGCs (Sakamoto, Liu et al. 2005).

\section{Dopamine, melatonin and refractive development}

\subsection{Dopamine}

Retinal dopamine levels are reduced during the induction of form-deprivation myopia in the chick (Stone, Lin et al. 1989), rhesus monkey (Iuvone, Tigges et al. 1991) and guinea pig (Mao, Liu et al. 2010). In the chick, this reduction is due to a decreased rate of dopamine synthesis during the light phase of the diurnal light:dark cycle (Stone, Lin et al. 1989). The use of modified translucent occluders demonstrates that retinal dopamine levels inversely correlate with the degree of axial elongation (Stone, Pendrak et al. 2006). Retinal dopamine levels exhibit a bidirectional response to retinal blur in chicks, with lens-induced myopia decreasing and hyperopia increasing the levels respectively (Guo, Sivak et al. 1995) although this effect is not universally reported (Bartmann, Schaeffel et al. 1994). The increase in retinal dopamine associated with the slowing of axial growth in 
lens-induced hyperopia parallels recovery from form-deprivation myopia in the chick where a similar relationship between dopamine level and axial growth is reported (Pendrak, Nguyen et al. 1997).

The role of dopamine in the control of ocular growth is further supported by the demonstration that ocular administration of dopamine agonists can inhibit the axial growth and myopic refractions produced by form-deprivation in chicks (Rohrer, Spira et al. 1993; Nickla, Totonelly et al. 2010) and primates (Iuvone, Tigges et al. 1991). Also, extraocular administration of the dopamine precursor levodopa by intraperitoneal injection in guinea pigs raises retinal dopamine content and reduces the development of myopia during formdeprivation (Mao, Liu et al. 2010). The relationship between retinal dopamine pathways and lens-induced myopia is less certain. At dosages sufficient to suppress form-deprivation myopia in chicks, development of lens-induced myopia was not suppressed by intra-vitreal injections of 6-hydroxy dopamine, a drug which inhibits dopaminergic pathways (Schaeffel, Hagel et al. 1994). Conversely the non-specific dopaminergic agonist apomorphine has been shown to block negative lens-induced myopia in other chick studies (Schmid and Wildsoet 2004; Nickla, Totonelly et al. 2010).

Investigations using dopamine receptor subtype-specific agonists and antagonists have shown that the antimyopiagenic effect of dopamine is primarily mediated by $\mathrm{D}_{2}$ receptors. For example, in form-deprivation in chicks, the protective effects of the non-specific dopaminergic agonist apomorphine were blocked by the $\mathrm{D}_{2}$ specific antagonist spiperone, but not by the $\mathrm{D}_{1}$ specific antagonist SCH-23390 (Rohrer, Spira et al. 1993).

In lens-induced myopia in chicks, both apomorphine (non-selective) and quinpirole $\left(\mathrm{D}_{2}\right.$ specific) agonists prevent the axial elongation and development of myopia associated with hyperopic defocus (Nickla, Totonelly et al. 2010). The effect is associated with an initial period of choroidal thickening, which is implicated in the inhibition of ocular growth either by the action of the choroid as a diffusion barrier to a growth signal or as an additional mechanical resistance to the effects of intraocular pressure (Nickla 2006). The $\mathrm{D}_{2}$ antagonist spiperone is not as effective in abolishing the protective effect of periodic lens removal as has been previously found for the removal of form-depriving diffusers in chicks (McCarthy, Megaw et al. 2007). This may suggest a partial role for $D_{1}$ receptors in the control of ocular growth (Nickla, Totonelly et al. 2010).

\subsection{Melatonin}

While experimental evidence supports the role of retinal dopamine in the control of ocular growth and in the protective effect of light on myopia development, the role of melatonin, with which it is intrinsically linked in a counterphase cycle, is less certain (Cahill and Besharse 1995; Witkovsky 2004; Iuvone, Tosini et al. 2005).

Evidence for the role of an intrinsic melatonin rhythm in the control of eye growth is provided by $\mathrm{Li}$ and Howland ( $\mathrm{Li}$ and Howland 2003) who demonstrated that the use of an opaque hood preventing light reaching the pineal gland for 12 hours per day is sufficient to significantly reduce the development of constant-light hyperopia in chicks. Covering one eye alone with an opaque occluder for 12 hours also partially prevented hyperopia development in the fellow eye under constant light conditions. The conclusion was that the eyes and pineal gland act as independent photoreceptors able to entrain the melatonin 
circadian rhythm which is protective against the effects of constant light on eye growth ( $\mathrm{Li}$ and Howland 2003).

While diurnal retinal melatonin rhythms appear unaffected during form-deprivation (Hoffmann and Schaeffel 1996), the intra-vitreal injection of melatonin at relatively high doses $(1000 \mu \mathrm{g})$ increases the level of form-deprivation myopia induced in the chick (Schaeffel, Bartmann et al. 1995; Hoffmann and Schaeffel 1996). Although retinal melatonin content was sampled twice a day (day and night) during monocular occlusion, and an expected diurnal variation in melatonin was found, no significant difference was found between the occluded and non-occluded eyes (Hoffmann and Schaeffel 1996). While the authors concluded that melatonin was not a significant component of the ocular growth control mechanism in form-deprivation in chicks a number of factors may have colluded to disguise the role of melatonin in form-deprivation myopia. These include the timing of the intra-vitreal injection of melatonin (between 2:00-3:00 pm) which may have occurred during a refractory period where the system was less sensitive, or that the duration (rather than the amplitude) of the nocturnal melatonin pulse may have been altered under form-deprivation conditions (see Section 4.7).

Rada and Wiechmann (Rada and Wiechmann 2006) demonstrated that the intraperitoneal injection of melatonin in chick at the beginning of each dark phase of the diurnal light cycle during a 5 day period of form-deprivation altered ocular growth patterns in both the formdeprived and control eyes. In form-deprived eyes, melatonin injection resulted in a significant reduction in anterior chamber depth, while vitreous chamber depth only exhibited a non-significant trend towards increased growth. The choroidal thickness was also significantly reduced in this group when compared to the sham-treatment group. The study also demonstrated the presence of melatonin receptors $\operatorname{Mel}(1 \mathrm{~A}), \operatorname{Mel}(1 \mathrm{~B})$ and $\operatorname{Mel}(1 \mathrm{C})$ in the cornea, choroid, sclera, and retina of the chick. A diurnal rhythm in the expression of these receptors was identified where $\operatorname{Mel}(1 \mathrm{C})$ expression was highest in the early morning around the onset of the light phase, while $\operatorname{Mel}(1 \mathrm{~A})$ and $\operatorname{Mel}(1 \mathrm{~B})$ expression was highest around the onset of the dark phase in the evenings. Rada and Wiechmann (Rada and Wiechmann 2006) concluded that the presence of melatonin receptors and diurnal rhythms of receptor expression, along with the effects of exogenous melatonin, suggests a significant role for melatonin in the control of ocular growth, and by extension, in the control of refractive development.

\section{Conclusion}

Recent human epidemiological studies propose that light exposure mediates the antimyopiagenic effect of outdoor activity. However, light may also have a causative role in myopia development when it is presented at an inappropriate time. Animal investigations demonstrate that light is a potent modulator of ocular growth and associated rhythms, including the interplay between dopamine and melatonin. One question is whether the effect of light on refractive development primarily acts through modification of circadian rhythms, or through some other intensity or wavelength dependent mechanism.

If the effect is circadian in origin, is there an optimal period for presenting light in order to control ocular growth and prevent myopia? Both constant light and constant dark disrupt ocular growth in animals and result in refractive error development. This can be 
ameliorated by either pharmacological interventions or controlled light exposure which reestablish more typical circadian rhythms. Light at night disrupts the normal circadian rhythm, rapidly decreasing melatonin and increasing dopamine, which potentially upsets the normal balance in ocular growth. As bright light presented in the middle of the day does not affect the timing of the circadian rhythm, presentation of a light signal during the twilight zones (dawn and dusk) is the most potent circadian zeitgeber. We hypothesise that the phase-advancing properties of morning light would be the most effective means of regulating the dopamine-melatonin circadian rhythm for the purposes of myopia control.

If the effect is not circadian in origin, then does the timing of the light signal matter or is it the nature of the stimulus (intensity and/or wavelength) that is important? Time spent outdoors leads to a significantly greater light dose than that received indoors, resulting in greater melatonin suppression and an increase in retinal dopamine. Additionally, the blue light spectral bias of outdoor light preferentially stimulates the melanopsin-containing ipRGCs, which would also lead to greater melatonin suppression. Both the intensity and wavelength of outdoor light favour increased retinal dopamine levels at the expense of melatonin. We hypothesise that it is this bias towards retinal dopamine production when outdoors that influences human refractive development, because increased dopamine has antimyopiagenic effects in animal experiments.

While the adage 'day-light good, night-light bad' in relation to refractive development is appealing, the true relationship between light and myopia is likely to be far more complex, with intricate interactions between the circadian cycle and the timing, intensity, and wavelength of the light exposure.

\section{Acknowledgements}

Simon Backhouse was supported by the New Zealand Association of Optometrists Education and Research Fund.

\section{References}

Adachi, A., T. Nogi, et al. (1998). "Phase-relationship and mutual effects between circadian rhythms of ocular melatonin and dopamine in the pigeon." Brain Res 792(2): 361369.

Alarma-Estrany, P. and J. Pintor (2007). "Melatonin receptors in the eye: location, second messengers and role in ocular physiology." Pharmacol Ther 113(3): 507-522.

Anstice, N. S. and J. R. Phillips (2011). "Effect of dual-focus soft contact lens wear on axial myopia progression in children." Ophthalmology 118(6): 1152-1161.

Aoki, H., N. Yamada, et al. (1998). "Minimum light intensity required to suppress nocturnal melatonin concentration in human saliva." Neurosci Lett 252(2): 91-94.

Ashby, R., A. Ohlendorf, et al. (2009). "The effect of ambient illuminance on the development of deprivation myopia in chicks." Invest Ophthalmol Vis Sci 50(11): 5348-5354.

Ashby, R. S. and F. Schaeffel (2010). "The effect of bright light on lens compensation in chicks." Invest Ophthalmol Vis Sci 51(10): 5247-5253. 
Axelrod, J. (1974). "The pineal gland: a neurochemical transducer." Science 184(144): 13411348.

Backhouse, S., H. Ng, et al. (2011). Light exposure patterns in children: a pilot study. Proceedings of the 13th International Myopia Conference, Tübingen, Germany, Optom Vis Sci 88(3): 395-403.

Balsalobre, A. (2002). "Clock genes in mammalian peripheral tissues." Cell Tissue Res 309(1): 193-199.

Bartmann, M., F. Schaeffel, et al. (1994). "Constant light affects retinal dopamine levels and blocks deprivation myopia but not lens-induced refractive errors in chickens." Vis Neurosci 11(2): 199-208.

Bernard, M., S. J. Donohue, et al. (1995). "Human hydroxyindole-O-methyltransferase in pineal gland, retina and Y79 retinoblastoma cells." Brain Res 696(1-2): 37-48.

Berson, D. M., F. A. Dunn, et al. (2002). "Phototransduction by retinal ganglion cells that set the circadian clock." Science 295(5557): 1070-1073.

Binkley, S., S. E. Macbride, et al. (1975). "Regulation of pineal rhythms in chickens: refractory period and nonvisual light perception." Endocrinology 96(4): 848-853.

Bittman, E. L. and F. J. Karsch (1984). "Nightly duration of pineal melatonin secretion determines the reproductive response to inhibitory day length in the ewe." Biol Reprod 30(3): 585-593.

Brainard, G. C., J. P. Hanifin, et al. (2001). "Action spectrum for melatonin regulation in humans: evidence for a novel circadian photoreceptor." J Neurosci 21(16): 6405-6412.

Brainard, G. C. and W. W. Morgan (1987). "Light-induced stimulation of retinal dopamine: a dose-response relationship." Brain Res 424(1): 199-203.

Cahill, G. M. and J. C. Besharse (1992). "Light-sensitive melatonin synthesis by Xenopus photoreceptors after destruction of the inner retina." Vis Neurosci 8(5): 487-490.

Cahill, G. M. and J. C. Besharse (1995). "Circadian rhythmicity in vertebrate retinas: Regulation by a photoreceptor oscillator." Prog Retin Eye Res 14(1): 267-291.

Charman, W. N. (2011). "Myopia, posture and the visual environment." Ophthalmic Physiol Opt. 31(5):494-501

Chua, W. H., V. Balakrishnan, et al. (2006). "Atropine for the treatment of childhood myopia." Ophthalmology 113(12): 2285-2291.

Cohen, J., M. Hadjiconstantinou, et al. (1983). "Activation of dopamine-containing amacrine cells of retina: light-induced increase of acidic dopamine metabolites." Brain Res 260(1): 125-127.

Cohen, Y., M. Belkin, et al. (2008). "Light intensity modulates corneal power and refraction in the chick eye exposed to continuous light." Vision Res 48(21): 2329-2335.

Cohen, Y., M. Belkin, et al. (2011). "Dependency between light intensity and refractive development under light-dark cycles." Exp Eye Res 92(1):40-46.

Coon, S. L., E. Del Olmo, et al. (2002). "Melatonin synthesis enzymes in Macaca mulatta: focus on arylalkylamine N-acetyltransferase (EC 2.3.1.87)." J Clin Endocrinol Metab 87(10): 4699-4706.

Czepita, D., W. Goslawski, et al. (2004). "Role of light emitted by incandescent or fluorescent lamps in the development of myopia and astigmatism." Med Sci Monit 10(4): CR168-171. 
Daan, S. and C. S. Pittendrigh (1976). "A Functional Analysis of Circadian Pacemakers in Nocturnal Rodents. II. The Variability of Phase Response Curves." J Comp Physiol 106(3): 253-266.

Di Paolo, T., C. Harnois, et al. (1987). "Assay of dopamine and its metabolites in human and rat retina." Neurosci Lett 74(2): 250-254.

Dirani, M., M. Chamberlain, et al. (2006). "Refractive errors in twin studies." Twin Res Hum Genet 9(4): 566-572.

Dirani, M., L. Tong, et al. (2009). "Outdoor activity and myopia in Singapore teenage children." Br J Ophthalmol 93(8): 997-1000.

Doyle, S. E., M. S. Grace, et al. (2002). "Circadian rhythms of dopamine in mouse retina: the role of melatonin." Vis Neurosci 19(5): 593-601.

Duane, A. (1919). Fuch's Textbook of Ophthalmology. Philadelphia, Lippincott.

Figueiro, M. G., M. S. Rea, et al. (2006). "Circadian effectiveness of two polychromatic lights in suppressing human nocturnal melatonin." Neurosci Lett 406(3): 293-297.

Flitcroft, D. I. (1990). "A neural and computational model for the chromatic control of accommodation." Vis Neurosci 5(6): 547-555.

Goldman, B. D. (2001). "Mammalian photoperiodic system: formal properties and neuroendocrine mechanisms of photoperiodic time measurement." J Biol Rhythms 16(4): 283-301.

Gottlieb, M. D., L. A. Fugate-Wentzek, et al. (1987). "Different visual deprivations produce different ametropias and different eye shapes." Invest Ophthalmol Vis Sci 28(8): 12251235.

Guerlotte, J., P. Greve, et al. (1996). "Hydroxyindole-O-methyltransferase in the chicken retina: immunocytochemical localization and daily rhythm of mRNA." Eur J Neurosci 8(4): 710-715.

Guggenheim, J. A., C. Hill, et al. (2003). "Myopia, genetics, and ambient lighting at night in a UK sample." Br J Ophthalmol 87(5): 580-582.

Guler, A. D., J. L. Ecker, et al. (2008). "Melanopsin cells are the principal conduits for rodcone input to non-image-forming vision." Nature 453(7191): 102-105.

Gunduz, B. and M. H. Stetson (2001). "A test of the coincidence and duration models of melatonin action in Siberian hamsters: the effects of 1-hr melatonin infusions on testicular development in intact and pinealectomized prepubertal Phodopus sungorus." J Pineal Res 30(2): 97-107.

Guo, S. S., J. G. Sivak, et al. (1995). "Retinal dopamine and lens-induced refractive errors in chicks." Curr Eye Res 14(5): 385-389.

Guyton, D. L., P. R. Greene, et al. (1989). "Dark-rearing interference with emmetropization in the rhesus monkey." Invest Ophthalmol Vis Sci 30(4): 761-764.

Gwiazda, J., L. Hyman, et al. (2003). "A randomized clinical trial of progressive addition lenses versus single vision lenses on the progression of myopia in children." Invest Ophthalmol Vis Sci 44(4): 1492-1500.

Gwiazda, J., E. Ong, et al. (2000). "Myopia and ambient night-time lighting." Nature 404(6774): 144. 
Hashimoto, S., K. Nakamura, et al. (1996). "Melatonin rhythm is not shifted by lights that suppress nocturnal melatonin in humans under entrainment." Am J Physiol 270(5 Pt 2): R1073-1077.

Hattar, S., H. W. Liao, et al. (2002). "Melanopsin-containing retinal ganglion cells: architecture, projections, and intrinsic photosensitivity." Science 295(5557): 10651070 .

Hattar, S., R. J. Lucas, et al. (2003). "Melanopsin and rod-cone photoreceptive systems account for all major accessory visual functions in mice." Nature 424(6944): 76-81.

Hazlerigg, D. G. and G. C. Wagner (2006). "Seasonal photoperiodism in vertebrates: from coincidence to amplitude." Trends Endocrinol Metab 17(3): 83-91.

Higuchi, S., Y. Motohashi, et al. (2007). "Less exposure to daily ambient light in winter increases sensitivity of melatonin to light suppression." Chronobiol Int 24(1): 31-43.

Hoffmann, M. and F. Schaeffel (1996). "Melatonin and deprivation myopia in chickens." Neurochem Int 28(1): 95-107.

Illnerova, H., M. Backstrom, et al. (1978). "Melatonin in rat pineal gland and serum; rapid parallel decline after light exposure at night." Neurosci Lett 9(2-3): 189-193.

Inouye, S. T. and H. Kawamura (1979). "Persistence of circadian rhythmicity in a mammalian hypothalamic "island" containing the suprachiasmatic nucleus." Proc Natl Acad Sci U S A 76(11): 5962-5966.

Iuvone, P. M. and J. C. Besharse (1986). "Dopamine receptor-mediated inhibition of serotonin N-acetyltransferase activity in retina." Brain Res 369(1-2): 168-176.

Iuvone, P. M., C. L. Galli, et al. (1978). "Light stimulates tyrosine hydroxylase activity and dopamine synthesis in retinal amacrine neurons." Science 202(4370): 901-902.

Iuvone, P. M., M. Tigges, et al. (1991). "Effects of apomorphine, a dopamine receptor agonist, on ocular refraction and axial elongation in a primate model of myopia." Invest Ophthalmol Vis Sci 32(5): 1674-1677.

Iuvone, P. M., G. Tosini, et al. (2005). "Circadian clocks, clock networks, arylalkylamine Nacetyltransferase, and melatonin in the retina." Prog Retin Eye Res 24(4): 433-456.

Jacobsen, N., H. Jensen, et al. (2008). "Does the level of physical activity in university students influence development and progression of myopia? - A 2-year prospective cohort study." Invest Ophthalmol Vis Sci 49(4): 1322-1327.

Jones, L. A., L. T. Sinnott, et al. (2007). "Parental history of myopia, sports and outdoor activities, and future myopia." Invest Ophthalmol Vis Sci 48(8): 3524-3532.

Kakita, T., T. Hiraoka, et al. (2011). "Influence of overnight orthokeratology on axial elongation in childhood myopia." Invest Ophthalmol Vis Sci 52(5): 2170-2174.

Kang, S. W., A. Thayananuphat, et al. (2007). "Dopamine-melatonin neurons in the avian hypothalamus controlling seasonal reproduction." Neuroscience 150(1): 223-233.

Khaldy, H., J. Leon, et al. (2002). "Circadian rhythms of dopamine and dihydroxyphenyl acetic acid in the mouse striatum: effects of pinealectomy and of melatonin treatment." Neuroendocrinology 75(3): 201-208.

Kramer, S. G. (1971). "Dopamine: A retinal neurotransmitter. I. Retinal uptake, storage, and light-stimulated release of H3-dopamine in vivo." Invest Ophthalmol 10(6): 438-452. 
Kroger, R. H. and H. J. Wagner (1996). "The eye of the blue acara (Aequidens pulcher, Cichlidae) grows to compensate for defocus due to chromatic aberration." J Comp Physiol A 179(6): 837-842.

Larsen, J. S. (1971). "The sagittal growth of the eye. IV. Ultrasonic measurement of the axial length of the eye from birth to puberty." Acta Ophthalmol 49(6): 873-886.

Larsen, P. J., L. W. Enquist, et al. (1998). "Characterization of the multisynaptic neuronal control of the rat pineal gland using viral transneuronal tracing." Eur J Neurosci 10(1): 128-145.

Lerner, A. B., J. D. Case, et al. (1958). "Isolation of Melatonin, the Pineal Gland Factor That Lightens Melanocytes." J Am Chem Soc 80(10): 2587-2587.

Levi, F. and U. Schibler (2007). "Circadian rhythms: mechanisms and therapeutic implications." Annu Rev Pharmacol Toxicol 47: 593-628.

Lewy, A. J., R. L. Sack, et al. (1987). "Antidepressant and circadian phase-shifting effects of light." Science 235(4786): 352-354.

Lewy, A. J., R. L. Sack, et al. (1985). "Immediate and delayed effects of bright light on human melatonin production: shifting "dawn" and "dusk" shifts the dim light melatonin onset (DLMO)." Ann N Y Acad Sci 453: 253-259.

Li, T. and H. C. Howland (2003). "The effects of constant and diurnal illumination of the pineal gland and the eyes on ocular growth in chicks." Invest Ophthalmol Vis Sci 44(8): 3692-3697.

Li, T., H. C. Howland, et al. (2000). "Diurnal illumination patterns affect the development of the chick eye." Vision Res 40(18): 2387-2393.

Li, T., D. Troilo, et al. (1995). "Constant light produces severe corneal flattening and hyperopia in chickens." Vision Res 35(9): 1203-1209.

Lin, L. L., Y. F. Shih, et al. (2004). "Prevalence of myopia in Taiwanese schoolchildren: 1983 to 2000." Ann Acad Med Singapore 33(1): 27-33.

Liu, J., K. Pendrak, et al. (2004). "Emmetropisation under continuous but non-constant light in chicks." Exp Eye Res 79(5): 719-728.

Liu, R., Y. F. Qian, et al. (2011). "Effects of different monochromatic lights on refractive development and eye growth in guinea pigs." Exp Eye Res. 92(6):447-453

Liu, T. and J. Borjigin (2005). "N-acetyltransferase is not the rate-limiting enzyme of melatonin synthesis at night." J Pineal Res 39(1): 91-96.

Loman, J., G. E. Quinn, et al. (2002). "Darkness and near work: myopia and its progression in third-year law students." Ophthalmology 109(5): 1032-1038.

Long, Q., D. Chen, et al. (2009). "Illumination with monochromatic long-wavelength light promotes myopic shift and ocular elongation in newborn pigmented guinea pigs." Cutan Ocul Toxicol 28(4): 176-180.

Luft, W. A., P. M. Iuvone, et al. (2004). "Spatial, temporal, and intensive determinants of dopamine release in the chick retina." Vis Neurosci 21(4): 627-635.

Lynch, H. J., D. C. Jimerson, et al. (1978). "Entrainment of rhythmic melatonin secretion in man to a 12-hour phase shift in the light/dark cycle." Life Sci 23(15): 1557-1563.

Mandel, Y., I. Grotto, et al. (2008). "Season of birth, natural light, and myopia." Ophthalmology 115(4): 686-692. 
Mandelman, T. and J. G. Sivak (1983). "Longitudinal chromatic aberration of the vertebrate eye." Vision Res 23(12): 1555-1559.

Mao, J., S. Liu, et al. (2010). "Levodopa inhibits the development of form-deprivation myopia in guinea pigs." Optom Vis Sci 87(1): 53-60.

Martin, X. D., H. Z. Malina, et al. (1992). "The ciliary body - the third organ found to synthesize indoleamines in humans." Eur J Ophthalmol 2(2): 67-72.

Maywood, E. S., R. C. Buttery, et al. (1990). "Gonadal responses of the male Syrian hamster to programmed infusions of melatonin are sensitive to signal duration and frequency but not to signal phase nor to lesions of the suprachiasmatic nuclei." Biol Reprod 43(2): 174-182.

McCarthy, C. S., P. Megaw, et al. (2007). "Dopaminergic agents affect the ability of brief periods of normal vision to prevent form-deprivation myopia." Exp Eye Res 84(1): 100-107.

McIntyre, I. M., T. R. Norman, et al. (1989). "Human melatonin suppression by light is intensity dependent." J Pineal Res 6(2): 149-156.

McMahon, G., T. Zayats, et al. (2009). "Season of Birth, Daylight Hours at Birth, and High Myopia." Ophthalmology. 116(3):468-473

Megaw, P. L., M. G. Boelen, et al. (2006). "Diurnal patterns of dopamine release in chicken retina." Neurochem Int 48(1): 17-23.

Melamed, E., Y. Frucht, et al. (1984). "Dopamine turnover in rat retina: a 24-hour lightdependent rhythm." Brain Res 305(1): 148-151.

Morgan, I. G. and M. K. Boelen (1996). "A retinal dark-light switch: a review of the evidence." Vis Neurosci 13(3): 399-409.

Mutti, D. O., G. L. Mitchell, et al. (2002). "Parental myopia, near work, school achievement, and children's refractive error." Invest Ophthalmol Vis Sci 43(12): 3633-3640.

Neumann, T., C. Ziegler, et al. (2008). "Multielectrode array recordings reveal physiological diversity of intrinsically photosensitive retinal ganglion cells in the chick embryo." Brain Res 1207: 120-127.

Nickla, D. L. (2006). "The phase relationships between the diurnal rhythms in axial length and choroidal thickness and the association with ocular growth rate in chicks." $J$ Comp Physiol A Neuroethol Sens Neural Behav Physiol 192(4): 399-407.

Nickla, D. L., K. Totonelly, et al. (2010). "Dopaminergic agonists that result in ocular growth inhibition also elicit transient increases in choroidal thickness in chicks." Exp Eye Res 91(5): 715-720.

Nickla, D. L., C. Wildsoet, et al. (1998). "Visual influences on diurnal rhythms in ocular length and choroidal thickness in chick eyes." Exp Eye Res 66(2): 163-181.

Nickla, D. L., C. F. Wildsoet, et al. (2001). "Endogenous rhythms in axial length and choroidal thickness in chicks: implications for ocular growth regulation." Invest Ophthalmol Vis Sci 42(3): 584-588.

Norton, T. T., A. O. Amedo, et al. (2006). "Darkness causes myopia in visually experienced tree shrews." Invest Ophthalmol Vis Sci 47(11): 4700-4707.

Nowak, J. Z., A. Kazula, et al. (1992). "Melatonin increases serotonin N-acetyltransferase activity and decreases dopamine synthesis in light-exposed chick retina: in vivo 
evidence supporting melatonin-dopamine interaction in retina." J Neurochem 59(4): 1499-1505.

Nowak, J. Z., E. Zurawska, et al. (1989). "Melatonin and its generating system in vertebrate retina: circadian rhythm, effect of environmental lighting and interaction with dopamine." Neurochem Int 14(4): 397-406.

Ohngemach, S., M. Feldkaemper, et al. (2001). "Pineal control of the dopamine D2-receptor gene and dopamine release in the retina of the chicken and their possible relation to growth rhythms of the eye." J Pineal Res 31(2): 145-154.

Oishi, T., J. K. Lauber, et al. (1987). "Experimental myopia and glaucoma in chicks." Zoolog Sci 4: 455-464.

Osol, G. and B. Schwartz (1984). "Melatonin in the human retina." Exp Eye Res 38(2): 213-215.

Papastergiou, G. I., G. F. Schmid, et al. (1998). "Ocular axial length and choroidal thickness in newly hatched chicks and one-year-old chickens fluctuate in a diurnal pattern that is influenced by visual experience and intraocular pressure changes." Exp Eye Res 66(2): 195-205.

Parkinson, D. and R. R. Rando (1983). "Effect of light on dopamine turnover and metabolism in rabbit retina." Invest Ophthalmol Vis Sci 24(3): 384-388.

Pendrak, K., T. Nguyen, et al. (1997). "Retinal dopamine in the recovery from experimental myopia." Curr Eye Res 16(2): 152-157.

Perez-Leon, J. A., E. J. Warren, et al. (2006). "Synaptic inputs to retinal ganglion cells that set the circadian clock." Eur J Neurosci 24(4): 1117-1123.

Perlow, M. J., E. K. Gordon, et al. (1977). "The circadian variation in dopamine metabolism in the subhuman primate." J Neurochem 28(6): 1381-1383.

Perlow, M. J., S. M. Reppert, et al. (1980). "Photic regulation of the melatonin rhythm: monkey and man are not the same." Brain Res 182(1): 211-216.

Pitrosky, B., R. Kirsch, et al. (1995). "The photoperiodic response in Syrian hamster depends upon a melatonin-driven circadian rhythm of sensitivity to melatonin." J Neuroendocrinol 7(11): 889-895.

Prendergast, B. J., M. R. Gorman, et al. (2000). "Establishment and persistence of photoperiodic memory in hamsters." Proc Natl Acad Sci U S A 97(10): 5586-5591.

Proll, M. A., C. W. Kamp, et al. (1982). "Use of liquid chromatography with electrochemistry to measure effects of varying intensities of white light on DOPA accumulation in rat retinas." Life Sci 30(1): 11-19.

Provencio, I., I. R. Rodriguez, et al. (2000). "A novel human opsin in the inner retina." J Neurosci 20(2): 600-605.

Quinn, G. E., C. H. Shin, et al. (1999). "Myopia and ambient lighting at night." Nature 399(6732): 113-114.

Rada, J. A. and A. F. Wiechmann (2006). "Melatonin receptors in chick ocular tissues: implications for a role of melatonin in ocular growth regulation." Invest Ophthalmol Vis Sci 47(1): 25-33.

Revell, V. L. and D. J. Skene (2007). "Light-induced melatonin suppression in humans with polychromatic and monochromatic light." Chronobiol Int 24(6): 1125-1137.

Roenneberg, T. and R. G. Foster (1997). "Twilight times: light and the circadian system." Photochem Photobiol 66(5): 549-561. 
Rohrer, B., A. W. Spira, et al. (1993). "Apomorphine blocks form-deprivation myopia in chickens by a dopamine D2-receptor mechanism acting in retina or pigmented epithelium." Vis Neurosci 10(3): 447-453.

Rollag, M. D., P. L. O'Callaghan, et al. (1978). "Serum melatonin concentrations during different stages of the annual reproductive cycle in ewes." Biol Reprod 18(2): 279285.

Rose, K. A., I. G. Morgan, et al. (2008a). "Outdoor activity reduces the prevalence of myopia in children." Ophthalmology 115(8): 1279-1285.

Rose, K. A., I. G. Morgan, et al. (2008b). "Myopia, lifestyle, and schooling in students of Chinese ethnicity in Singapore and Sydney." Arch Ophthalmol 126(4): 527-530.

Ruby, N. F., T. J. Brennan, et al. (2002). "Role of melanopsin in circadian responses to light." Science 298(5601): 2211-2213.

Rucker, F. J. and J. Wallman (2009). "Chick eyes compensate for chromatic simulations of hyperopic and myopic defocus: evidence that the eye uses longitudinal chromatic aberration to guide eye-growth." Vision Res 49(14): 1775-1783.

Sakamoto, K., C. Liu, et al. (2005). "Dopamine regulates melanopsin mRNA expression in intrinsically photosensitive retinal ganglion cells." Eur J Neurosci 22(12): 3129-3136.

Saw, S. M., G. Gazzard, et al. (2005). "Myopia and associated pathological complications." Ophthalmic Physiol Opt 25(5): 381-391.

Saw, S. M., M. Z. Zhang, et al. (2002). "Near-work activity, night-lights, and myopia in the Singapore-China study." Arch Ophthalmol 120(5): 620-627.

Schade, R., K. Vick, et al. (1995). "Circadian rhythms of dopamine and cholecystokinin in nucleus accumbens and striatum of rats - influence on dopaminergic stimulation." Chronobiol Int 12(2): 87-99.

Schaeffel, F., M. Bartmann, et al. (1995). "Studies on the role of the retinal dopamine/melatonin system in experimental refractive errors in chickens." Vision Res 35(9): 1247-1264.

Schaeffel, F., G. Hagel, et al. (1994). "6-Hydroxy dopamine does not affect lens-induced refractive errors but suppresses deprivation myopia." Vision Res 34(2): 143-149.

Schmid, K. L. and C. F. Wildsoet (2004). "Inhibitory effects of apomorphine and atropine and their combination on myopia in chicks." Optom Vis Sci 81(2): 137-147.

Schwahn, H. N. and F. Schaeffel (1997). "Flicker parameters are different for suppression of myopia and hyperopia." Vision Res 37(19): 2661-2673.

Seidemann, A. and F. Schaeffel (2002). "Effects of longitudinal chromatic aberration on accommodation and emmetropization." Vision Res 42(21): 2409-2417.

Shaw, D. and B. D. Goldman (1995). "Influence of prenatal and postnatal photoperiods on postnatal testis development in the Siberian hamster (Phodopus sungorus)." Biol Reprod 52(4): 833-838.

Simonneaux, V. and C. Ribelayga (2003). "Generation of the melatonin endocrine message in mammals: a review of the complex regulation of melatonin synthesis by norepinephrine, peptides, and other pineal transmitters." Pharmacol Rev 55(2): 325395.

Smith, E. L., 3rd, D. V. Bradley, et al. (2001). "Continuous ambient lighting and eye growth in primates." Invest Ophthalmol Vis Sci 42(6): 1146-1152. 
Smith, K. A., M. W. Schoen, et al. (2004). "Adaptation of human pineal melatonin suppression by recent photic history." J Clin Endocrinol Metab 89(7): 3610-3614.

Sowers, J. R. and N. Vlachakis (1984). "Circadian variation in plasma dopamine levels in man." J Endocrinol Invest 7(4): 341-345.

Stone, R. A., T. Lin, et al. (1995). "Photoperiod, early post-natal eye growth, and visual deprivation." Vision Res 35(9): 1195-1202.

Stone, R. A., T. Lin, et al. (1989). "Retinal dopamine and form-deprivation myopia." Proc Natl Acad Sci U S A 86(2): 704-706.

Stone, R. A., K. Pendrak, et al. (2006). "Local patterns of image degradation differentially affect refraction and eye shape in chick." Curr Eye Res 31(1): 91-105.

Tast, A., R. J. Love, et al. (2001). "The pattern of melatonin secretion is rhythmic in the domestic pig and responds rapidly to changes in daylength." J Pineal Res 31(4): 294300.

Thapan, K., J. Arendt, et al. (2001). "An action spectrum for melatonin suppression: evidence for a novel non-rod, non-cone photoreceptor system in humans." J Physiol 535(Pt 1): 261-267.

Thomas, K. B., M. Tigges, et al. (1993). "Melatonin synthesis and circadian tryptophan hydroxylase activity in chicken retina following destruction of serotonin immunoreactive amacrine and bipolar cells by kainic acid." Brain Res 601(1-2): 303307.

Torii, M., D. Kojima, et al. (2007). "Two isoforms of chicken melanopsins show blue light sensitivity." FEBS Lett 581(27): 5327-5331.

Tosini, G. and J. C. Dirden (2000). "Dopamine inhibits melatonin release in the mammalian retina: in vitro evidence." Neurosci Lett 286(2): 119-122.

Tosini, G. and M. Menaker (1996). "Circadian rhythms in cultured mammalian retina." Science 272(5260): 419-421.

Tosini, G., N. Pozdeyev, et al. (2008). "The circadian clock system in the mammalian retina." Bioessays 30(7): 624-633.

Vannas, A. E., G. S. Ying, et al. (2003). "Myopia and natural lighting extremes: risk factors in Finnish army conscripts." Acta Ophthalmol Scand 81(6): 588-595.

Vitale, S., R. D. Sperduto, et al. (2009). "Increased prevalence of myopia in the United States between 1971-1972 and 1999-2004." Arch Ophthalmol 127(12): 1632-1639.

Wang, F., J. Zhou, et al. (2011). "Effects of $530 \mathrm{~nm}$ Green Light on Refractive Status, Melatonin, MT1 Receptor, and Melanopsin in the Guinea Pig." Curr Eye Res 36(2): 103-111.

Weiler, R., W. H. Baldridge, et al. (1997). "Modulation of endogenous dopamine release in the fish retina by light and prolonged darkness." Vis Neurosci 14(2): 351-356.

Weiss, S. and F. Schaeffel (1993). "Diurnal growth rhythms in the chicken eye: relation to myopia development and retinal dopamine levels." J Comp Physiol A Neuroethol Sens Neural Behav Physiol 172(3): 263-270.

Wiechmann, A. F. and J. G. Hollyfield (1987). "Localization of hydroxyindole-Omethyltransferase-like immunoreactivity in photoreceptors and cone bipolar cells in the human retina: a light and electron microscope study." J Comp Neurol 258(2): 253-266. 
Wilkinson, M., J. Arendt, et al. (1977). "Determination of a dark-induced increase of pineal $\mathrm{N}$-acetyl transferase activity and simultaneous radioimmunoassay of melatonin in pineal, serum and pituitary tissue of the male rat." J Endocrinol 72(2): 243-244.

Witkovsky, P. (2004). "Dopamine and retinal function." Doc Ophthalmol 108(1): 17-39.

Zadnik, K., L. A. Jones, et al. (2000). "Myopia and ambient night-time lighting. CLEERE Study Group. Collaborative Longitudinal Evaluation of Ethnicity and Refractive Error." Nature 404(6774): 143-144.

Zawilska, J. B., D. J. Skene, et al. (2009). "Physiology and pharmacology of melatonin in relation to biological rhythms." Pharmacol Rep 61(3): 383-410.

Zeitzer, J. M., D. J. Dijk, et al. (2000). "Sensitivity of the human circadian pacemaker to nocturnal light: melatonin phase resetting and suppression." J Physiol $526 \mathrm{Pt}$ 3: 695702.

Zmijewski, M. A., T. W. Sweatman, et al. (2009). "The melatonin-producing system is fully functional in retinal pigment epithelium (ARPE-19)." Mol Cell Endocrinol 307(1-2): 211-216. 


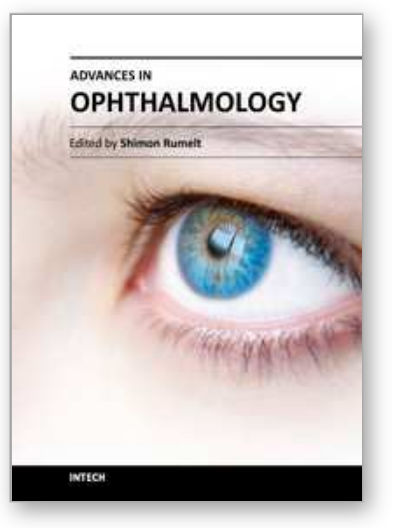

\author{
Advances in Ophthalmology \\ Edited by Dr Shimon Rumelt
}

ISBN 978-953-51-0248-9

Hard cover, 568 pages

Publisher InTech

Published online 07, March, 2012

Published in print edition March, 2012

This book focuses on the different aspects of ophthalmology - the medical science of diagnosis and treatment of eye disorders. Ophthalmology is divided into various clinical subspecialties, such as cornea, cataract, glaucoma, uveitis, retina, neuro-ophthalmology, pediatric ophthalmology, oncology, pathology, and oculoplastics. This book incorporates new developments as well as future perspectives in ophthalmology and is a balanced product between covering a wide range of diseases and expedited publication. It is intended to be the appetizer for other books to follow. Ophthalmologists, researchers, specialists, trainees, and general practitioners with an interest in ophthalmology will find this book interesting and useful.

\title{
How to reference
}

In order to correctly reference this scholarly work, feel free to copy and paste the following:

John R. Phillips, Simon Backhouse and Andrew V. Collins (2012). Myopia, Light and Circadian Rhythms, Advances in Ophthalmology, Dr Shimon Rumelt (Ed.), ISBN: 978-953-51-0248-9, InTech, Available from: http://www.intechopen.com/books/advances-in-ophthalmology/myopia-light-and-circadian-rhythms

\section{INTECH}

open science | open minds

\section{InTech Europe}

University Campus STeP Ri

Slavka Krautzeka 83/A

51000 Rijeka, Croatia

Phone: +385 (51) 770447

Fax: +385 (51) 686166

www.intechopen.com

\section{InTech China}

Unit 405, Office Block, Hotel Equatorial Shanghai

No.65, Yan An Road (West), Shanghai, 200040, China

中国上海市延安西路65号上海国际贵都大饭店办公楼 405 单元

Phone: +86-21-62489820

Fax: +86-21-62489821 
(C) 2012 The Author(s). Licensee IntechOpen. This is an open access article distributed under the terms of the Creative Commons Attribution 3.0 License, which permits unrestricted use, distribution, and reproduction in any medium, provided the original work is properly cited. 